\title{
Power Efficiency Improvement of the Composite Resonant DC-DC Converter
}

\author{
Hisatsugu Kato ${ }^{*}$ and Yoichi Ishizuka ${ }^{\dagger}$ \\ *Power Electronics Engineering Department \\ Tabuchi Electric CO., LTD Osaka 532-0007, Japan \\ Tel: +81-6-4807-3535, Fax: +81-6-4807-3534 \\ E-mail: h.kato@zbr.co.jp \\ ${ }^{\dagger}$ Nagasaki University, Nagasaki, 852-8521, Japan \\ E-mail: isy2@nagasaki-u.ac.jp
}

\begin{abstract}
This paper deals with the power efficiency improvement of the composite resonant DC-DC converter, which is developed to be applied to the power conditioner of the photovoltaic generation system. To improve the power efficiency, following three approaches are taken: 1) optimum design of the transformer 2) use of the voltage doubler rectifier. 3) reduction of the winding loss of the transformer. The maximum power efficiency of $98.0 \%$ can be realized.
\end{abstract}

Keywords-component; power efficiency improvement, composite resonant $\mathrm{DC}-\mathrm{DC}$ converter, optimum design, voltage doubler rectifier, leakage flux

\section{INTRODUCTION}

Of all the energy used all over the world, the fossil energy from such as oil, coal and natural gas is the largest in number, which emits the carbon dioxide that causes global warming.. As a result, abnormal weather, the rise of a sea surface and so forth are predicted. To solve this problem, great attention to the new energy resources such as the photovoltaic cell, fuel cell and wind force are are given.

This paper deals with the power efficiency improvement of the composite resonant DC-DC converter[1-4], which is developed to be applied to the power conditioner of the photovoltaic generation system. To improve the power efficiency, following three approaches are examined:

(1) Optimum design of the transformer with reducing the size and weight of the transformer

(2) Use of voltage doubler rectifier

(3) Reduction of the winding loss caused by the leakage flux in the vicinity of the air gap of the transformer

\section{CIRCUIT CONFIGURATION}

Fig.1 shows the proposed current resonant DC-DC converter with the voltage doubler rectifier, in which the current and voltage resonant circuits are employed. In this figure, TR1 and TR2 are main switches of MOSFETs. CTR1

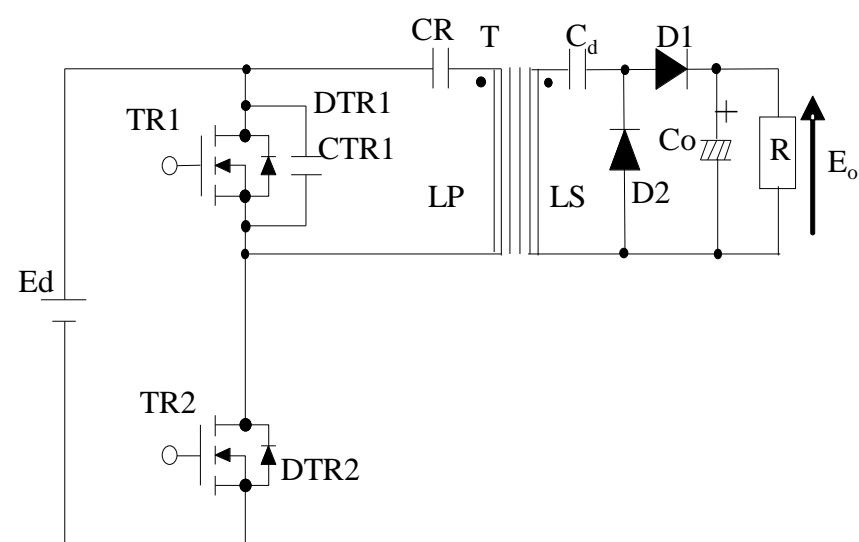

Fig. 1 Half-bridge current resonance DC- DC converter with the voltage doubler rectifier.

and CR are the voltage and current resonance capacitors, respectively. LP and LS are inductances of the primary and secondary windings of the transformer $\mathrm{T}$. The voltage doubler rectifier is composed of the diodes D1 and D2, and capacitances Cd and Co. The MOSFET switches TR1 and TR2 are turned-on and turned-off alternatively. There exists the short dead time between the on-times of TR1 and TR2. The photovoltaic generation system has the output capacity of $2 \mathrm{~kW}$. The DC-DC converter requirements are 80-450V input voltage, $396 \mathrm{~V}$ output voltage and $2150 \mathrm{~W}$ maximum input power.

\section{POWER EFFICIENCY IMPROVEMENT}

A. Optimum design for the transformer (Reducing the transformer's size and weight.)

To realize both of improvement of power efficiency and downsizing of the DC-DC converter, optimization of transformer is performed.

The comparison of specifications with conventional one is summarized in Table 1. In Table 2, the compared results for categorized power consumption of the optimized transformer and conventional one are summarized. From these results, the volume and weight of $57 \%$ of the optimized trans-former can be reduced, compared to the conventional one. By downsizing 
Table 1 Specifications of DC-DC converter of the optimized transformer and conventional one.

\begin{tabular}{|l|c|c|}
\hline & The optimized & Conventional \\
\hline Transformer form & PQ50 & PQ71 \\
\hline Air gap & $1.2 \mathrm{~mm}$ & $1.5 \mathrm{~mm}$ \\
\hline $\begin{array}{l}\text { Diameter and turn of } \\
\text { Primary winding with } \\
\text { litz wire }\end{array}$ & $0.06 \mathrm{~mm} / 1350$ turn & $0.12 \mathrm{~mm} / 504$ turn \\
$\begin{array}{l}\text { Diameter and turn of } \\
\text { Secondary winding } \\
\text { with litz wire }\end{array}$ & $0.06 \mathrm{~mm} / 810 \mathrm{turn}$ & $0.12 \mathrm{~mm} / 252 \mathrm{turn}$ \\
\hline Resonant Capacitor & $1.16 \mu \mathrm{F}$ & $0.88 \mu \mathrm{F}$ \\
\hline
\end{tabular}

Table 2 Power consumption and power efficiency comparison of the optimized transformer and conventional one.

\begin{tabular}{|l|c|c|}
\hline & $\begin{array}{l}\text { Optimized } \\
\text { transformer }(\mathrm{W})\end{array}$ & $\begin{array}{l}\text { Conventional } \\
\text { transformer }(\mathrm{W})\end{array}$ \\
\hline $\begin{array}{l}\text { MOSFET (High + Low) } \\
\text { conduction loss }\end{array}$ & 11.0 & 10.0 \\
\hline $\begin{array}{l}\text { MOSFET (High + Low) } \\
\text { switching loss }\end{array}$ & 1.2 & 11.2 \\
\hline $\begin{array}{l}\text { Rectifier diode loss ( } D_{1} \text { and } \\
\left.D_{2}\right)\end{array}$ & 12.0 & 0.9 \\
\hline $\begin{array}{l}\text { Rectifier diode loss ( } D_{1}, \\
\left.\text { and } D_{2}\right)\end{array}$ & 0.7 & 2.3 \\
\hline $\begin{array}{l}\text { Winding copper loss } \\
\text { (Primary) }\end{array}$ & 4.5 & 2.2 \\
\hline $\begin{array}{l}\text { Winding copper loss } \\
(\text { Secondary) }\end{array}$ & 6.5 & 24.3 \\
\hline The other winding losses & 13.7 & 5.5 \\
\hline Loss of EMC filters & 5.5 & 3 \\
\hline Other losses & 3.0 & $97.2 \% \quad($ Total loss \\
\hline $\begin{array}{l}\text { Power efficiency (250V } \\
\text { 2150W) }\end{array}$ & $97.3 \%$ (Total loss \\
\hline
\end{tabular}

of transformer, winding copper loss is increased, but otherwise the other winding losses, including iron loss and proximity effect loss, are become almost a half. As the result, downsizing of the transformer is realized with the increasing of $0.1 \%$ power efficiency. Precise descriptions are described in later.

\section{B. Employing the voltage doubler rectifier.}

To compare the recovery loss of voltage doubler rectifier and center tapped rectifier, the requirements are settled with $210 \mathrm{~V}$ input voltage, $180 \mathrm{~V}$ output voltage and $1 \mathrm{~kW}$ output power. Figure 4 shows the conventional half bridge current

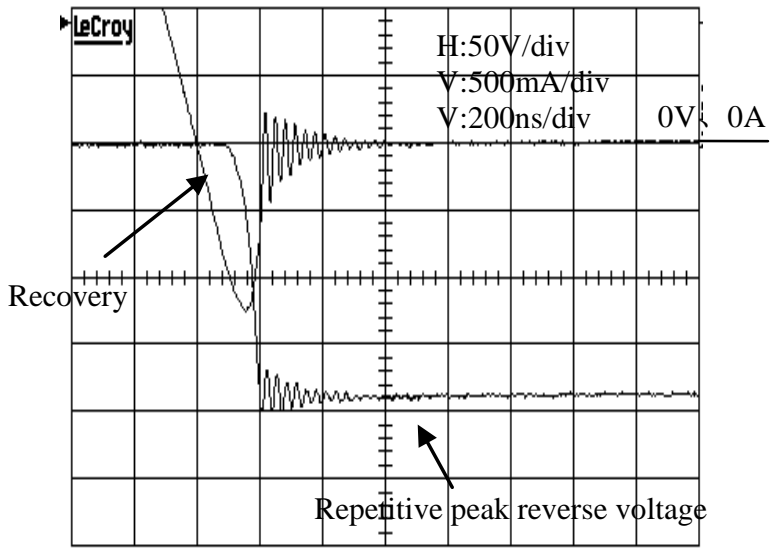

Fig. 2 Voltage doubler rectifier.

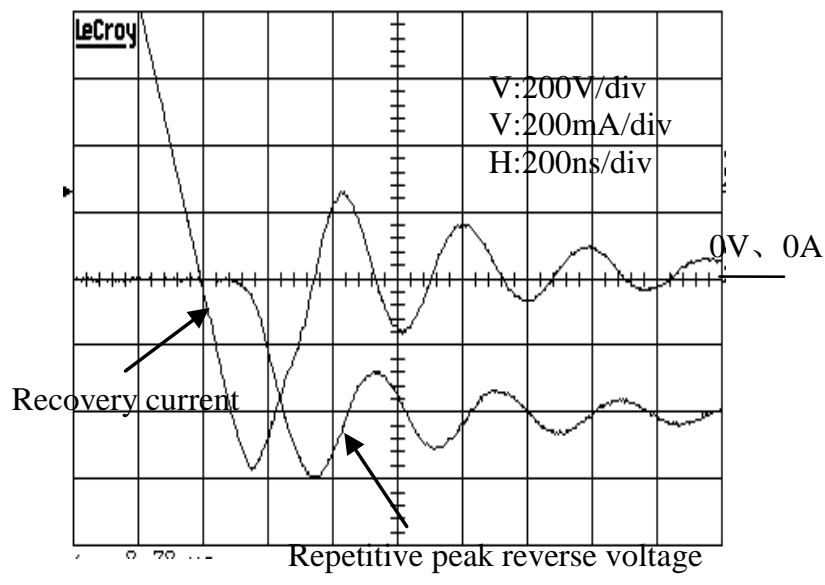

Fig. 3 Center tapped rectifier.

resonance DC-DC converter with the center tapped rectifier. In the experiment, FRD of the maximum reverse voltage $600 \mathrm{~V}$ is used as a rectifier diode. The requirements are maximum requirements to avoid over avoid maximum reverse voltage of FRD.

In Figs. 2 and 3, the waveforms of voltage and current of the voltage doubler and the center-tapped rectifier are shown, respectively. Each of the recovery loss is $0.42 \mathrm{~W}$ and $0.94 \mathrm{~W}$, respectively. The rectifier loss is reduced in half. The recovery loss of diodes is reduced by employing the voltage doubler rectifier in the secondary side as shown in Fig. 1. By the capacitor $C_{\mathrm{d}}$ in the voltage doubler, the reverse current loss is reduced.

Another advantage of the voltage doubler rectifier is it can be able to treat more power than the center tapped rectifier.

From the experimental result, the maximum output power was $2150 \mathrm{~W}$ with $250 \mathrm{~V}$ input voltage, $400 \mathrm{~V}$ reverse voltage. Also, the recovery loss is almost $0.4 \mathrm{~W}$. The reverse voltage is clumped to regulated voltage between output voltage and secondary voltage of transformer. Therefore, the loss occurred by the oscillation is suppressed. Same result is realized with full bridge rectifier, but the number of diodes and heat sink are increased. The both of cost and difficulty of the circuit implementation are increasing.

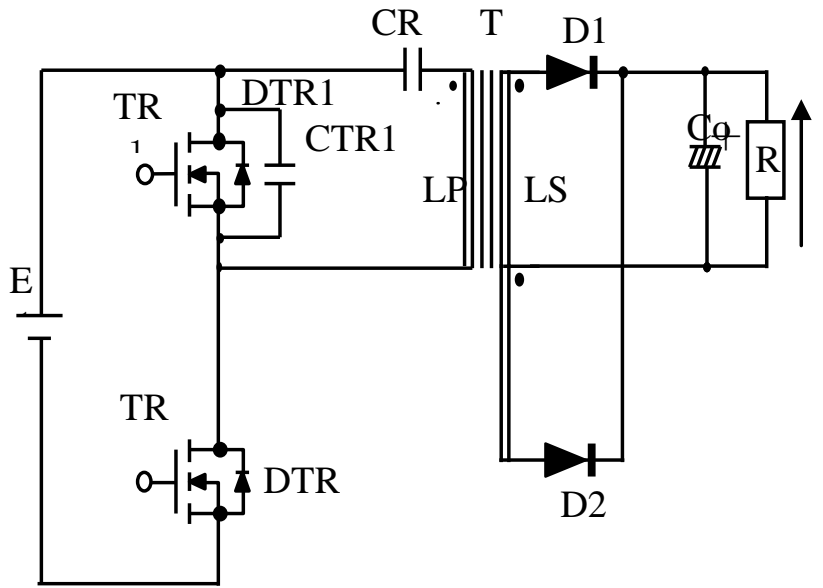

Fig. 4 The half bridge current resonance DC-DC converter with the Center tap rectifier. 


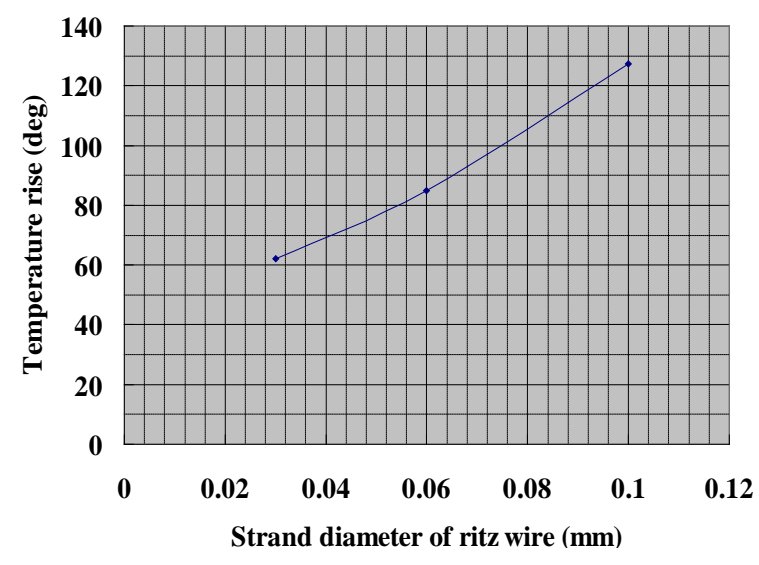

Fig. 5 Temperature rise vs. strand diameter of the litz wire

C. Reduction of the winding loss by the leakage flux in the vicinity of the air gap of the transformer

The leakage flux in the vicinity of the air gap of the transformer intersects with the winding. Then eddy-current loss and loss due to proximity effect are caused. If the switching frequency increases with the rise of the input voltage, these losses increase. It is presumed as described above. In order to solve this problem, as shown in Fig. 5, temperature rise of winding is improved by making the strand diameter of the litz wire small. That is, the loss by winding is reduced and the power efficiency is improved. The magnetic analysis using simulation was performed. The simulation was performed to avoid the memory overflow with simplified settings that bundle litz wires are unified to $0.8 \mathrm{~mm}$ wire.

Figure 6 shows simulation results. Each figure shows the magnetic field variation at $\theta=0$ deg., $\theta=45$ deg. and $\theta=90$ deg. The applied input alternative current is cosine waveform, that peak value is at 0 deg. ,

Typically, winding loss is simply categorized to skin depth loss, eddy current loss and proximity effect loss. The simulation results are analyzed with this categorization.

The diameter of litz wire using in experiments is $0.06 \mathrm{~mm}$. $0.06 \mathrm{~mm}$ of the diameter size is decided as the minimum limit of mass productivity. The estimated skin depth is calculated $0.19 \mathrm{~mm}$ with switching frequency $120 \mathrm{kHz}$. Therefore, the skin depth effect and loss can be ignored. Also, the test is performed with putting litz wire near to air gap. From the result, there was any generating heat in litz wire, that is, eddy current loss is able to be ignored.

After all, it can be thought that the most of winding loss is occurred by proximity effect.

\section{POWER EFFICIENCY}

Fig. 7 shows the power efficiency characteristics of the composite resonant DC-DC converter. It is seen that the power
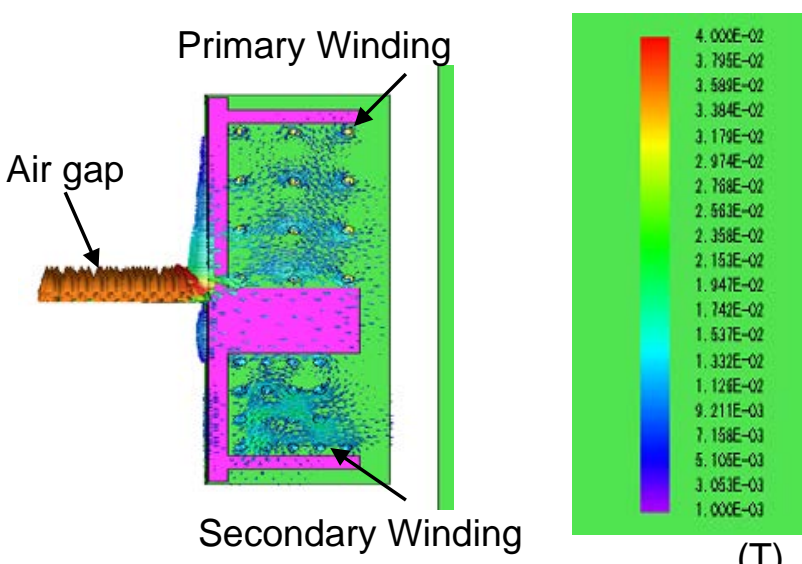

(a) $\theta=0$ deg. (Peak Primary Current)
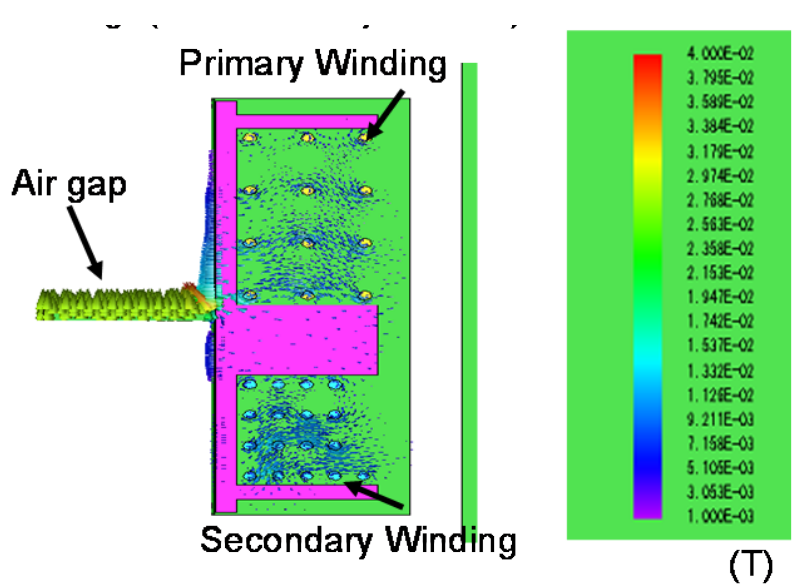

(b) $\theta=45 \mathrm{deg}$.
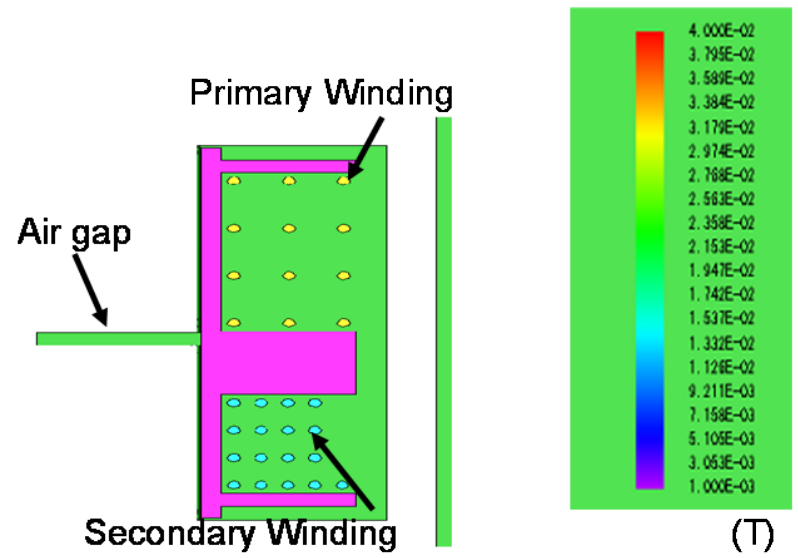

(T)

(c) $\theta=90 \mathrm{deg}$. (Zero Primary Current)

Fig. 6 The magnetic analysis results. 


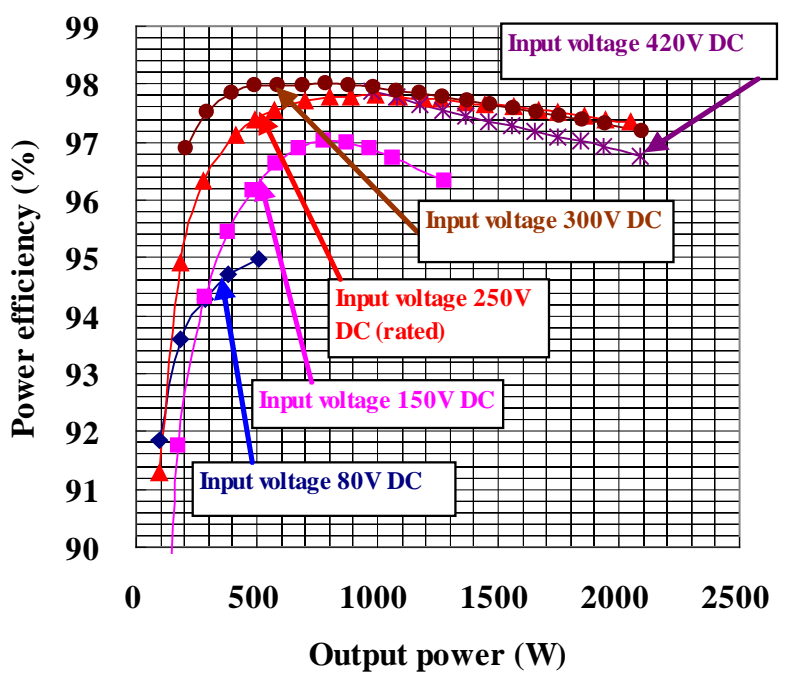

Fig. 7 Power efficiency of the proposed composite resonant DC-DC converter.

efficiency is very high and that the maximum power efficiency of $98.0 \%$ can be realized at $300 \mathrm{~V}$ DC of the input voltage. Then the output voltage is $380 \mathrm{~V}$ DC. The high power efficiency over $97.0 \%$ can be realized from $150 \mathrm{~V} \mathrm{DC}$ to $420 \mathrm{~V}$ DC of the input voltage and the high power efficiency over $97.0 \%$ can be realized at $250 \mathrm{~V}$ DC (rated) of the input voltage and from $400 \mathrm{~W}$ to $2150 \mathrm{~W}$ of the input power.

\section{CONCLUSION}

From the above discussion, the high power efficiency is obtained using the proposed half.-bridge current resonance DC-DC converter. The maximum power efficiency is very high and $98 \%$ when the input voltage is $300 \mathrm{~V} \mathrm{DC}$. The power efficiency of $97 \%$ is realized at $250 \mathrm{~V} \mathrm{DC}$ (rated) of the input voltage and from $400 \mathrm{~W}$ to $2,150 \mathrm{~W}$ of the input power.

The improvement has been done with:

(1) Optimum design of the transformer with reducing the size and weight of the transformer

(2) Use of voltage doubler rectifier

(3) Reduction of the winding loss caused by the leakage flux in the vicinity of the air gap of the transformer

\section{REFERENCES}

[1]Daisuke Yodhitomi, Junichi Itoh, Katsuya, Hirachi, "Relationship between Leakage Inductance and Surge Voltage on Isolated DCDC Converter", Journal of the Japan Institute of Powere Electronics, vol,37,pp.66-80,2011

[2]Koichi Morita,"Ultra Low-noise switch-mode Power Supply”, Journal of Japan Institute of Power Electronics, Vol.30, pp4-11, March 2004

[3]Hiroto Mizutani, Tomokazu Mishima, Yasuyuki Ooue, Yoshiki Fukumoto, Mutsuo Nakaoka,'Fundamental Analysis for LLC Resonant DC-DC Converter with a Reverse Multi-resonant LC Filter on Characteristics of DC Voltage Conversion Ratio”,Japan Institute of Power Electronics, Vol.37,pp168-174,2011

[4]C.F.JIN,T.Ninomiya,S.Tomioka,”Dynamic Characteristics of LLC Current-Resonant DC-DC Converter”, IEICE Technical Report, EE2008-35,pp.1-6,October 2008 